1 Artigo parcialmente desenvolvido com apoio da FAPESP, processo número 2014/04168-6.

\section{Considerações acerca do conceito de projeto de produtos interativos na contemporaneidade. Processo de criação e desenvolvimento do aplicativo Crewee'.}

\author{
Considerations about contemporary concepts of \\ interactive product design. Processes of creation \\ and development of Crewee application.
}

Adeline G. S. Gil, Antonio J. M. L. Lourenço, Hermes R. Hildebrand

design, processo de criação, gerenciamento, método, interação.

Design, process of creation, management, method, interaction.

\begin{abstract}
Nesse artigo, descrevemos o processo de criação e desenvolvimento do aplicativo Crewee, uma plataforma de criação em conjunto e suporte para a tomada de decisões projetuais, voltada para estúdios de design, agências de publicidade, artistas, arquitetos e outros profissionais envolvidos com a cultura de projeto. Partimos de um panorama sobre os processos tradicionais desenvolvimento de projetos descritos na literatura da área de design, destacando sua maior ou menor aplicabilidade no contexto atual de produção, em que os processos não partem de um problema bem definido, e sim, fazem com que o problema de projeto seja constantemente redefinido no decorrer do processo, com a entrada de novas informações. Em seguida, fazemos considerações sobre o próprio conceito de projeto e do conjunto de métodos para a criação de produtos interativos na contemporaneidade, principalmente devido ao aumento de complexidade das variáveis envolvidas no processo de projeto, sendo uma delas a criação colaborativa e a apropriação do inesperado como oportunidade de expandir as possibilidades do produto.
\end{abstract}

In this article, we describe the processes of creation and development of Crewee application, a platform for creating together and a support for making project decisions, aimed at design studios, advertising agencies, artists, architects and other professionals involved with the culture of project. We start from an overview of the traditional processes of project development described in the literature of design, highlighting their greater or lesser applicability in the current context of production, in which the processes do not start from a well-defined problem: in this context, the design problem is constantly redefined in the process, with the entry of new information. Then, we present considerations on the concept of design and on the set of methods for creating interactive products nowadays, mainly due to the increasing complexity of the variables involved in the design process, such as the collaborative creation and the appropriation of the unexpected as an opportunity to expand the possibilities of the product. 


\section{Introdução}

2 Em uma das mais importantes empresas de design no mundo, o IDEO, o espaço projetual envolve três campos de atividades: inspiração, idealização e implementação (BROWN, 2010).
O termo "método" pode ser entendido como um ordenamento de tarefas para a solução de um problema. Esse ordenamento pode ter diversos modos e, de modo geral, a literatura da área de design identifica o processo com a "concatenação do problema com uma alternativa de solução" (Vieira, 2009). Dessa forma, o processo deve equacionar os mais diversos requisitos de projeto na direção de uma solução.

Os primeiros estudos registram uma concepção linear desse ordenamento (como em Archer, apud Van Der Linden, et al, 2010), que posteriormente deram lugar a concepções mais sistêmicas do processo. Nos modelos lineares, possíveis retornos ou retroalimentações eram vistos como problema ou possibilidade de corrigir eventuais problemas. Já nos modelos cíclicos (como no IDEO²), “são necessárias iterações sucessivas para que o problema e a solução sejam modelados. À ideia de evolução paralela entre o problema e solução é dado o nome de coevolução" (Van Der Linden, 2010: 1631). Foi dessa forma, nos termos de uma co-evolução, que o processo de concepção e desenvolvimento do aplicativo Crewee se deu, como será detalhado no capítulo 3 deste artigo.

Na década de 1960 começam a surgir os modelos de gerenciamento baseados em fases de desenvolvimento de produtos, e foram evoluindo simultaneamente na academia e no mercado, visando não apenas estabelecer as funções do produto, mas principalmente entender o produto no seu contexto de uso. Isso culminou na integração entre áreas aparentemente separadas, como filosofia, ciência e arte, para lidar com o aumento da complexidade dos produtos e processos de produção na contemporaneidade.

O nível de definição do problema é uma variável importante a ser considerada para a definição de uma estratégia. No caso do aplicativo Crewee, que será descrito mais adiante, partiu-se de uma definição preliminar do problema que, por sua vez, foi feita com base na experiência e na observação de necessidades recorrentes no dia a dia de trabalho dos designers envolvidos, articulando design e inovação.

\section{Breve panorama sobre métodos projetuais}

Vieira (2009) estabeleceu um estudo importante que sintetiza, no quadro abaixo, as principais metodologias atuais e destaca, ainda, que aquelas compreendidas entre os anos 1992 e 2002 têm forte caráter sistêmico, estruturação como modelo sequencial, certa versatilidade e abordagem metodológica cartesiana: 
Gil, A. G. S. , Lourenço, A. J. M. L. \& Hildebrand, H. R. | Considerações acerca do conceito de projeto de produtos interativos na contemporaneidade. Processo de criação e desenvolvimento do aplicativo Crewee

Tabela 1 Principais metodologias atuais. Fonte: VIEIRA, G. (2009). Disponível em: http://convergencias.esart.ipcb.pt/artigo/58.

\begin{tabular}{|c|c|c|c|}
\hline AUTOR & ANO & PROPOSTA & DIFERENCIAL \\
\hline BACK, N. & 1983 & $\begin{array}{l}\text { Aborda questões de } \\
\text { operacionalização } \\
\text { do produto } \\
\text { projetado, tais } \\
\text { como planejamento } \\
\text { de produção, } \\
\text { mercado, consumo } \\
\text { e obsolescência. }\end{array}$ & $\begin{array}{l}\text { Aponta que as } \\
\text { fases de um } \\
\text { projeto de produto } \\
\text { industrial podem } \\
\text { ser estabelecidas } \\
\text { de diferentes } \\
\text { formas com maior } \\
\text { ou menor grau } \\
\text { de detalhamento. } \\
\text { Aborda a gestão } \\
\text { e implementação } \\
\text { do projeto, } \\
\text { considerando } \\
\text { a obsolescência. }\end{array}$ \\
\hline MUNARI, B. & 1983 & $\begin{array}{l}\text { Abordagem de } \\
\text { projeto de forma } \\
\text { sequencial, de modo } \\
\text { bastante abrangente, } \\
\text { evidenciando a } \\
\text { lógica do processo } \\
\text { de design como } \\
\text { etapas gerais a } \\
\text { serem cumpridas } \\
\text { para a solução de } \\
\text { um problema. }\end{array}$ & $\begin{array}{l}\text { Destaca a } \\
\text { importância do } \\
\text { método na solução } \\
\text { de problemas de } \\
\text { projeto. Destaca } \\
\text { que a criatividade } \\
\text { não significa } \\
\text { improvisação sem } \\
\text { método e que } \\
\text { o problema de } \\
\text { design resulta de } \\
\text { uma necessidade. }\end{array}$ \\
\hline BONSIEPE, G. & 1984 & $\begin{array}{l}\text { Metodologia de } \\
\text { caráter acadêmico, } \\
\text { estabelece uma } \\
\text { sequencia de etapas } \\
\text { a serem seguidas, ao } \\
\text { longo do processo } \\
\text { de projeto. }\end{array}$ & $\begin{array}{l}\text { Coloca que a } \\
\text { metodologia é uma } \\
\text { ajuda no processo } \\
\text { projetual, destacando } \\
\text { técnicas e métodos } \\
\text { específicos em cada } \\
\text { etapa do projeto. }\end{array}$ \\
\hline BOMFIM, G. A. & 1984 & $\begin{array}{l}\text { Metodologia } \\
\text { para suprir a } \\
\text { complexidade } \\
\text { crescente das } \\
\text { variáveis envolvidas } \\
\text { em um projeto. }\end{array}$ & $\begin{array}{l}\text { Destaca cinco } \\
\text { pontos importantes: } \\
\text { designer, empresa, } \\
\text { consumidor, } \\
\text { sociedade e produto. }\end{array}$ \\
\hline ROSENBURG, N. & 1996 & $\begin{array}{l}\text { Aborda o produto } \\
\text { como um sistema } \\
\text { para a solução } \\
\text { de problemas. }\end{array}$ & $\begin{array}{l}\text { Enumera aspectos } \\
\text { relativos ao sistema } \\
\text { atrelado ao produto. } \\
\text { Destaca a etapa de } \\
\text { análise do sistema. }\end{array}$ \\
\hline BAXTER, M. & 1998 & $\begin{array}{l}\text { Aborda questões } \\
\text { vinculadas ao } \\
\text { mercado e ao } \\
\text { sucesso do } \\
\text { produto projetado. }\end{array}$ & $\begin{array}{l}\text { Articula design e } \\
\text { marketing com a } \\
\text { proposta de alcançar } \\
\text { diferenciação e um } \\
\text { projeto de caráter } \\
\text { inovador. Elenca uma } \\
\text { série de ferramentas } \\
\text { a serem empregadas } \\
\text { em um projeto } \\
\text { de design. }\end{array}$ \\
\hline
\end{tabular}


Gil, A. G. S. , Lourenço, A. J. M. L. \& Hildebrand, H. R. | Considerações acerca do conceito de projeto de produtos interativos na contemporaneidade. Processo de criação e desenvolvimento do aplicativo Crewee

\begin{tabular}{|l|l|l|l|}
\hline LÖBACH, B. & 2000 & $\begin{array}{l}\text { Aponta que o } \\
\text { processo de } \\
\text { design é tanto um } \\
\text { processo criativo } \\
\text { como de solução } \\
\text { de problemas. }\end{array}$ & $\begin{array}{l}\text { Destaca a lógica de } \\
\text { avanços e retrocessos } \\
\text { ao longo do processo } \\
\text { de design. }\end{array}$ \\
\hline BITTENCOURT, A. & 2001 & $\begin{array}{l}\text { Projeto a partir do } \\
\text { estabelecimento de } \\
\text { um problema oriundo } \\
\text { de uma necessidade } \\
\text { dos usuários. }\end{array}$ & $\begin{array}{l}\text { Volta-se para os } \\
\text { usuários como } \\
\text { direcionamento das } \\
\text { ações de projeto. }\end{array}$ \\
\hline ABRAMOVITZ,J. & 2002 & $\begin{array}{l}\text { Gestão do processo } \\
\text { de projeto por } \\
\text { meio do controle } \\
\text { das etapas. Aborda } \\
\text { o método como } \\
\text { um instrumento } \\
\text { que orienta o } \\
\text { desenvolvimento de } \\
\text { um produto de forma } \\
\text { segura e efetiva. }\end{array}$ & $\begin{array}{l}\text { Aponta a } \\
\text { especificação de } \\
\text { metas, requisitos } \\
\text { e restrições do } \\
\text { projeto. Apresenta } \\
\text { uma abordagem de } \\
\text { gestão do processo } \\
\text { de projeto por } \\
\text { meio de montagem } \\
\text { e execução de } \\
\text { cronograma } \\
\text { de desenvolvimento. }\end{array}$ \\
\hline
\end{tabular}

3 Tais como: design e emoção (Norman, 2004), inovação pelo design (Utterback, 2007; Verganti, 2008), ergonomia, processo criativo, entre outros. Podemos incluir aqui: design thinking (Brown, 2010); design de interação (Preece; Rogers; Sharp, 2005) e design da experiência do usuário (Shedroff, 2001), entre outros.

$4 \mathrm{O}$ conceito de metaprojeto será aprofundado no item 2.1. do presente artigo.

5 Fonte: http://leanstack. com/. Acesso em 21 Set. 2014.
O autor salienta que é preciso ter o cuidado de não situar o design como uma atividade de caráter técnico e meramente operacional, em função de um problema definido, principalmente porque grande parte da especificidade dessa profissão envolve o exercício analítico, crítico e criativo do projeto. As metodologias atuais devem estar integradas com o pensamento atual de gestão do design, inovação e sustentabilidade. Nesse sentido, para o autor, há outras referências mais próximas das linhas e correntes específicas do design ${ }^{3}$.

Vieira propõe, então, um método que considera os três níveis de atuação do design: o nível estratégico, ou ainda, o metaprojeto ${ }^{4}$ (entrada, pesquisa contextual e pesquisa aberta), onde também se define o conceito do projeto; o nível tático (sistematização dos dados, ou "como fazer") e o nível técnico e operacional (geração de alternativas, finalização e avaliação).

No caso do aplicativo Crewee, enquanto produto, trata-se de uma nova experiência para os usuários, portanto, seu processo de desenvolvimento necessariamente contemplou esses três níveis de atuação. Além disso, Crewee pode ser considerado um negócio, mais que um produto. Nesse sentido, destacamos o Business Model Generation ${ }^{5}$, um manual prático para melhorar um negócio já existente ou criar um novo negócio, bastante utilizado por startups. 
Gil, A. G. S. , Lourenço, A. J. M. L. \& Hildebrand, H. R. | Considerações acerca do conceito de projeto de produtos interativos na contemporaneidade. Processo de criação e desenvolvimento do aplicativo Crewee

\subsection{O Metadesign e a instauração de um nicho de interação}

Faz-se necessário, nesse momento, explicitar o conceito de metaprojeto ou metadesign (Vassão, 2010; Moraes, 2010) e aproximá-lo da realidade da produção de um produto interativo que também é um serviço, como o Crewee.

Para Vassão, a maioria dos métodos e abordagens do Design de Interação é proveniente das ciências exatas ou das engenharias, que têm uma relação instrumental com o cotidiano, procurando controlar seu funcionamento, "debelar as multiplicidades que sempre se proliferam na vida urbana e social” (ibid., p. 18) e, como forma de evitar esse reducionismo, algumas vertentes direcionam suas abordagens pelas ciências sociais, mas ainda sem reconhecer a filosofia como a base de todas as ciências, assim como sem reconhecer a complexidade como uma realidade de trabalho para os profissionais da cultura de projeto.

Sendo assim, três sentidos para o termo metadesign são expostos pelo autor: a) o sentido de um movimento reflexivo ("o design do design"), ou ainda, considerando o prefixo "meta" como "além", indicando um movimento de transposição: "projetos que possam operar a transposição de princípios de projeto de um contexto a outro" (ibid., p. 19); b) como um objeto intermediário, um ambiente de decisões, ou ainda, um "projeto de segunda ordem", no qual as entidades são abstratas (como, por exemplo, regras, diretrizes, requisitos); c) um sentido ligado ao processo de autopoiese (autocriação): "a criação de uma entidade por meio de operações que ela engendra em si mesma" (ibid., p. 21).

Cremos que o segundo sentido (b) está em sintonia com a forma com que o Crewee foi pensado e desenvolvido, uma vez que a fase de definição do problema, sendo já uma ação criativa, foi o momento de maior engajamento da equipe de designers e desenvolvedores, visando atender a uma necessidade de forma inovadora. A ação do metadesign é produzir a arquitetura de decisões - arquitetura no sentido de "Sistema e/ou Entidade Complexa Fundamental" (ibid., p. 94, grifos do autor), ou seja, construir o campo de ação do projeto.

Já o terceiro sentido (c) nos parece ser a forma como o

6 Versão beta disponível para download gratuito: http://www.crewee.com/

7 Essas ideias fazem parte de uma área do conhecimento denominada Ecologia das Mídias, e tem em McLuhan, Innis e Neil Postman como principais representantes (Vassão, 2010: 73) produto poderá evoluir a partir da disponibilização da versão beta, gratuitamente, a milhares de usuários, de forma a descentralizar o processo e contar com a colaboração de usuários ${ }^{6}$.

Reconhecer a complexidade envolve abdicar do controle absoluto do processo de projeto, e isso iria contra ao "que se considera fundamental do processo de projeto: o controle sobre os resultados das intenções projetuais" (ibid., p. 68). A noção de emergência, do ponto de vista cultural, implica que toda inovação, ao ser lançada à sociedade, afetará a cultura de modo surpreendente ${ }^{7}$. Cabe ao projetista aproveitar os imprevistos, até mesmo fomentá-los, liberá-los "das amarras de uma organização centralizada", inclusive como uma "atitude ética frente à alteridade, àquilo que emerge da sociedade e da cultura" (ibid., p, 79). 
Gil, A. G. S. , Lourenço, A. J. M. L. \& Hildebrand, H. R. | Considerações acerca do conceito de projeto de produtos interativos na contemporaneidade. Processo de criação e desenvolvimento do aplicativo Crewee

8 Baseados nas concepções de virtual, atual, possível e real de Pierre Lévy (1998), que por sua vez está em sintonia com os conceitos de Virtual e Atual na filosofia de Deleuze e Guattari.
Um exemplo bastante esclarecedor de como o projeto de um produto, serviço ou sistema não prevê todos os possíveis usos que se pode fazer dele, ou de como a emergência é um dado inevitável e deve ser vista como uma oportunidade, é como o computador pessoal foi construído perante a percepção do usuário. Surgiu como um objeto complexo, na forma de um kit, que era aparentemente confuso para o iniciante,

(...) sendo, em seguida, convertido em objeto de intensa experimentação: gradualmente, um conjunto muito amplo e variado de amadores desenvolveram uma miríade de periféricos, componentes e softwares que expandiram brutalmente sua funcionalidade (...) à revelia da ação de alguma corporação, instituição governamental, de pesquisa ou ensino" (Ceruzzi, 1998, apud Vassão, 2010: 113).

Objetos complexos da atualidade, denominados information appliances pela indústria cultural, integram produtos, serviços e sistemas, porém segundo o autor, tendem a ser operados de maneira mais determinada e menos aberta do que os kits.

A imprensa, criada inicialmente para acelerar o processo de produção de livros, também teve consequências imprevistas, que se revelaram pouco a pouco ao longo de 300 anos, tendo influência inclusive na emergência da Revolução Industrial (ibid. p. 73).

Seguindo essa linha de pensamento, o agenciamento inicial de um processo de projeto partiria, então, da identificação de uma possibilidade, não de uma necessidade, noção muito difundida no campo do design: que este deve "responder a uma necessidade". Para o autor, esse processo ainda é mal explicado na literatura do design. Dessa forma, propõe quadrívios cíclicos ${ }^{8}$ o o primeiro (Figura 1) se refere ao processo pelo qual uma inovação, tecnologia, novo produto ou serviço se dissemina pela sociedade, conformando um nicho de interação:

Figura 1 Conformação de um nicho de interação (Vassão, 2010: 80).

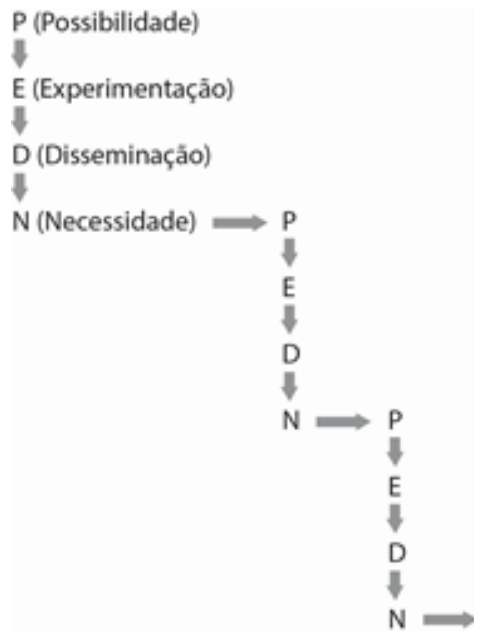


9 Apropriando-se do termo Ecologia das Mídias, o autor desenvolve esse desdobramento conceitual e o aplica ao design de interação, como o "conjunto de práticas interativas do cotidiano em que estamos imersos, e do qual participamos passivamente e ativamente". A Ecologia da Interação "é a conjunção entre tecnologia e sociedade que compõe um ambiente dotado de uma miríade de objetos e situações em que ocorre a interação", havendo nela relações específicas (nichos de interação) em que a interatividade ocorre (ibid., p. 79).
Parte-se da identificação de uma possibilidade (P), a partir de uma experimentação que envolve um agenciamento possível de tecnologias e a ecologia da interação existente ${ }^{9}$. Em seguida, um grupo restrito é responsável pela experimentação dessa inovação (E), e as relações entre as partes envolvidas é pouco formalizada. O momento seguinte é a disseminação no cotidiano (D): "conforma-se uma imagem da inovação, que circula pela sociedade como um objeto abstrato, compacto, de fácil reprodução" (ibid., p. 81, grifo do autor). Nesse momento, o processo de experimentação conta com precedentes e a formalização entre as partes envolvidas vai se delineando. No último estágio, a inovação já está de tal forma entranhada à vida social, que se torna uma necessidade, uma parte da ecologia da interação (a exemplo do smartphone). E o processo se reinicia, como pode ser visto com mais detalhes no segundo quadrívio (Figura 2):

Figura 2 Processo geral de instauração de um novo nicho de interação (ibid., p. 82).

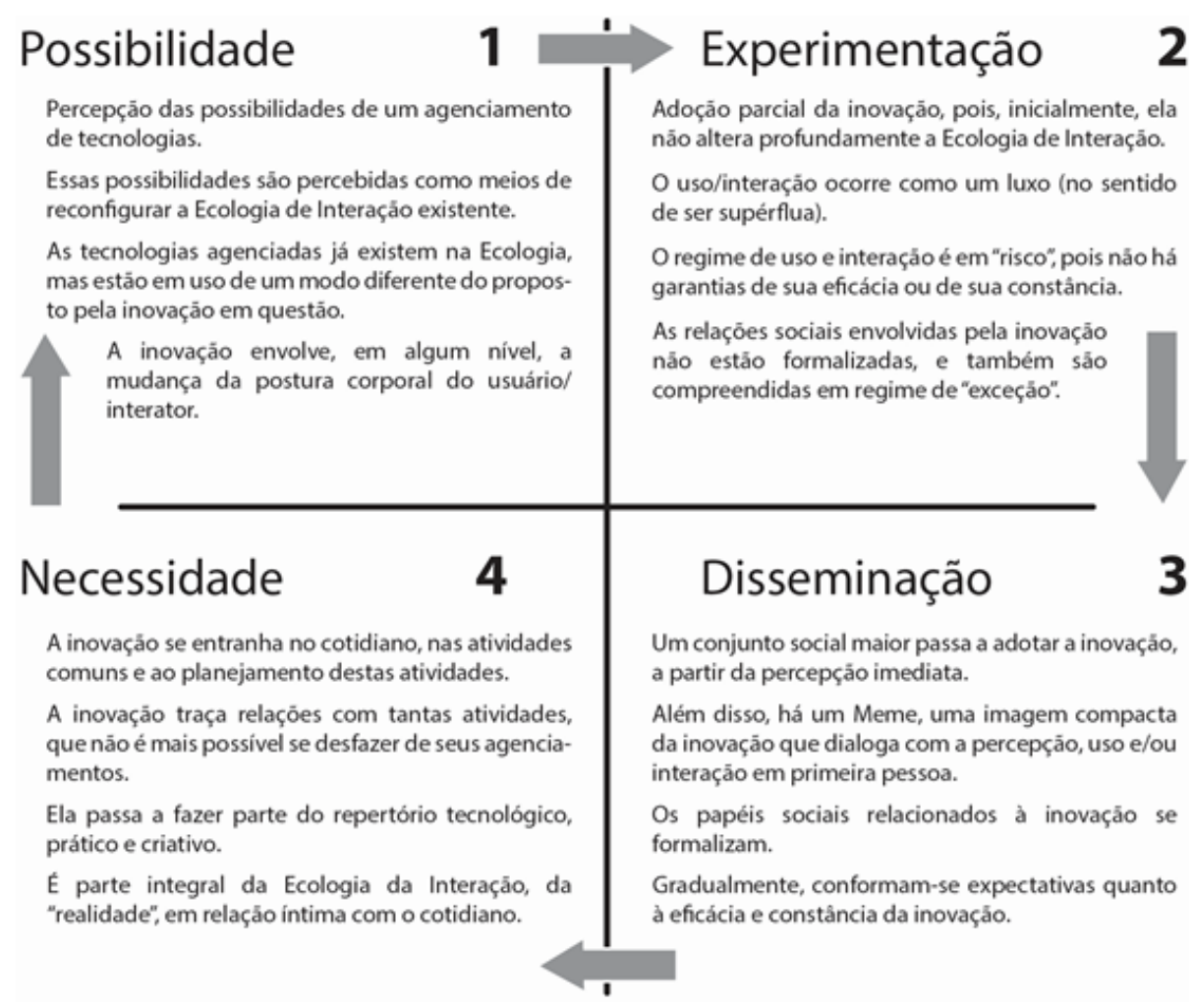

No caso do aplicativo Crewee, houve de fato a identificação de uma necessidade, ao mesmo tempo em que havia um contexto tecnológico, social e cultural perceptível (possibilidade), o que levou, num segundo momento, à sua elaboração, tendo-se em vista sua produção (experimentação). No terceiro momento, essa entidade foi tornada real (disseminação) na forma de uma versão beta e, após uma série de refinamentos, contando com o feedback dos usuários, o produto poderá fazer parte da ecologia da interação existente. 


\section{Concepção e desenvolvimento do aplicativo Crewee}

10 Há uma diferença significativa entre instrumento e ferramenta, segundo Vassão (2010: 104-

5). Ferramentas são participativas, interativas, dependem de como nos permitimos acoplar e implicam uma abertura à emergência de situações imprevistas. Já o instrumento está vinculado a premissas e objetivos predeterminados.

11 Por exemplo: Dot Project (http://www. dotproject.net/); Merlin (http://www. projectwizards.net/ en/merlin/) e Omni Plan (http://www. omnigroup.com/ omniplan). Acesso em: 23 Set. 2014.

12 Redpen: (https:// redpen.io/); Prevue (http://prevue. it/); Cage (http:// cageapp.com/) e In Vision (http:// www.invisionapp. com/). Acesso em: 23 Set. 2014.
O Crewee é uma ferramenta ${ }^{10}$ desenvolvida para dinamizar a atividade criativa de profissionais junto aos seus clientes, aprimorando a troca de informações e a experiência de criação em conjunto. Nasceu a partir da troca de vivências entre duas empresas após se conhecerem em um evento de fomento ao empreendedorismo no ambiente universitário. Após uma palestra do sócio-diretor da Quiçá Design, os integrantes da recém criada Yiom, empresa de desenvolvimento de sistemas, tiveram um contato mais profundo com o dia a dia de uma empresa de Design. Após várias conversas informais sobre os problemas enfrentados durante a criação dos projetos, as duas empresas decidiram desenvolver o Crewee.

Percebeu-se que um dos maiores problemas da empresa de design era o tempo gasto no alinhamento da equipe interna com as expectativas do cliente, não durante o briefing, e sim durante o decorrer do projeto. Por esse motivo, aconteciam várias "idas e vindas" do projeto, ou seja, existiam muitas refações. Por isso, pensou-se em desenvolver um software/aplicativo para ajudar nas trocas entre o cliente e a equipe de criação.

No senso comum, o projeto de design acontece em dois momentos distintos: 1) coleta do briefing junto ao cliente; 2) busca de solução pelo designer ou pela equipe. Isso é um grande equívoco e é a principal causa do grande número de refações. Ao não incluir o cliente na aplicação da metodologia projetual, na tentativa de acelerar o processo de criação, acaba-se atrasando ainda mais o projeto, já que na realidade o briefing (ou a entrada de informações) não acontece num só momento, e sim durante todas as etapas do projeto. Por esse motivo, as soluções pensadas para o Crewee visaram, principalmente, ações que incluíssem o cliente de uma maneira mais dinâmica no processo de criação e desenvolvimento.

Percebeu-se que, de modo geral, ferramentas de gerenciamento de projeto ${ }^{11}$ não são visuais: o registro é feito por escrito e a imagem tem uma importância secundária. No Crewee, pode-se afirmar que a base do gerenciamento é a imagem. Outros aplicativos foram analisados na fase de busca de referências positivas e negativas, na direção do que se almejou com o Crewee. São eles, ordenados do mais simples ao mais complexo: Redpen, Prevue, Cage e In Vision ${ }^{12}$. Observou-se que o Crewee é mais robusto que os dois primeiros e menos "burocrático" do que os dois últimos.

Ao acelerar, dinamizar as trocas de informação entre cliente e equipe de criação, percebeu-se que o problema poderia ser amenizado em sua maior parte ou até mesmo resolvido. 
Gil, A. G. S. , Lourenço, A. J. M. L. \& Hildebrand, H. R. | Considerações acerca do conceito de projeto de produtos interativos na contemporaneidade. Processo de criação e desenvolvimento do aplicativo Crewee

\subsection{Ações práticas: soluções no aplicativo}

Seguem abaixo, de forma sintetizada, as principais soluções presentes no Crewee:

a) Uso das prévias (imagens que sintetizam a solução da etapa projetual, ou "entregas"): decidiu-se que a base do aplicativo estaria no upload de imagens de forma cronológica, e que pudessem ser comentadas de modo visual e textual.

Figura 3 Tela do upload (direitos autorais: Quiçá Design. Direitos de uso concedidos para este artigo).

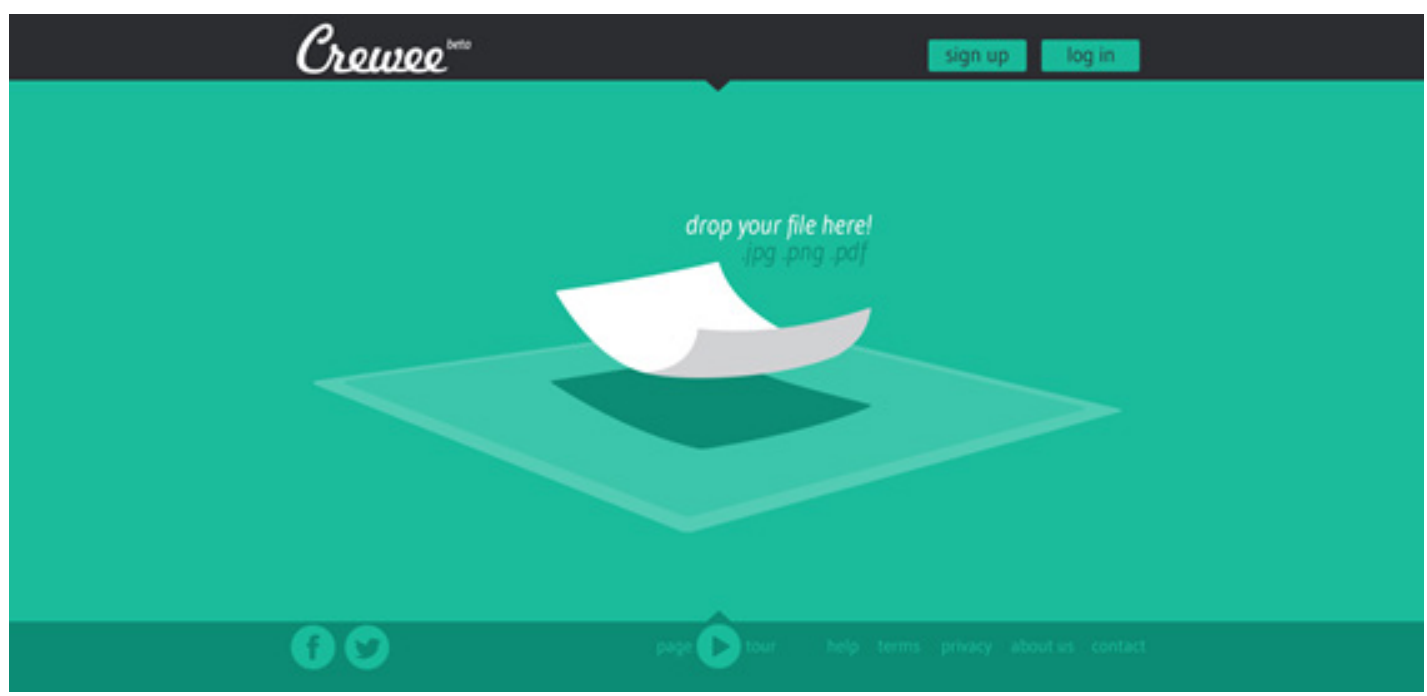

Figura 4 Tela da sequência cronológica. Comentários negativos sobre a fase atual (a fase atual é indicada abaixo pelas imagens em miniatura nomeadas como "Rendering"), aparecem em vermelho, no canto superior esquerdo da imagem; comentários positivos aparecem em verde no canto superior direito (direitos autorais: Quiçá Design. Direitos de uso concedidos para este artigo).
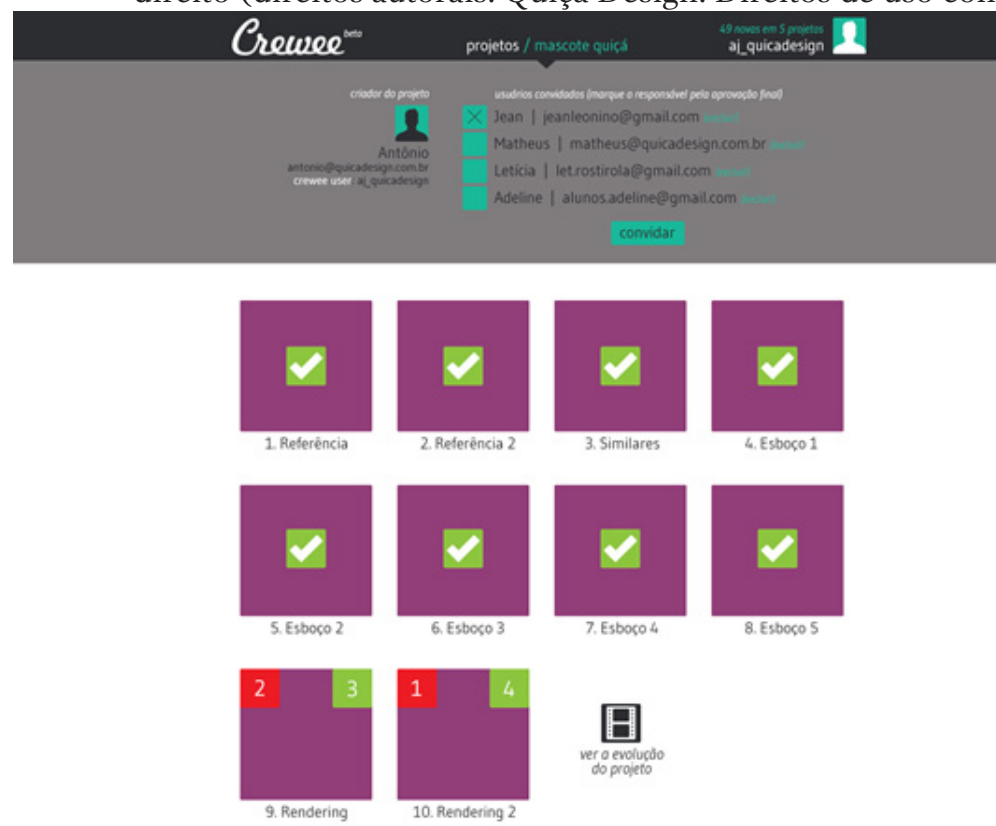
Gil, A. G. S. , Lourenço, A. J. M. L. \& Hildebrand, H. R. | Considerações acerca do conceito de projeto de produtos interativos na contemporaneidade. Processo de criação e desenvolvimento do aplicativo Crewee

Figura 5 Tela dos comentários na forma visual e textual. Cliente e equipe de criação podem desenhar diretamente sobre a imagem do projeto para fazer os comentários (direitos autorais: Quiçá Design. Direitos de uso concedidos para este artigo).
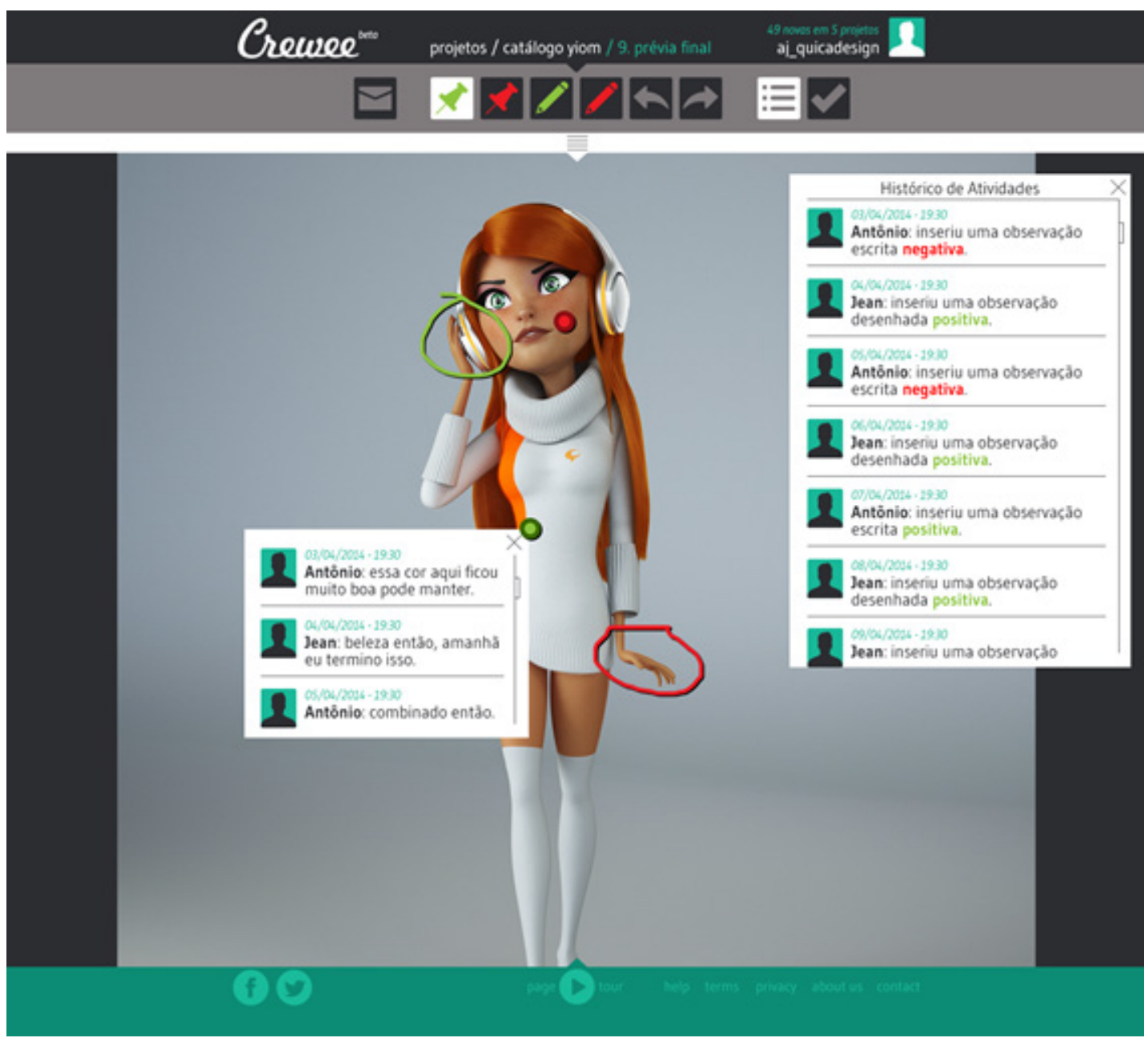

b) Aprovações em definitivo das prévias: após comentários e aprovações, o cliente autoriza o prosseguimento do projeto para a próxima etapa. 
Gil, A. G. S. , Lourenço, A. J. M. L. \& Hildebrand, H. R. | Considerações acerca do conceito de projeto de produtos interativos na contemporaneidade. Processo de criação e desenvolvimento do aplicativo Crewee

Figura 6 Figura 6: Tela da aprovação/validação da fase

(direitos autorais: Quiçá Design. Direitos de uso concedidos para este artigo).
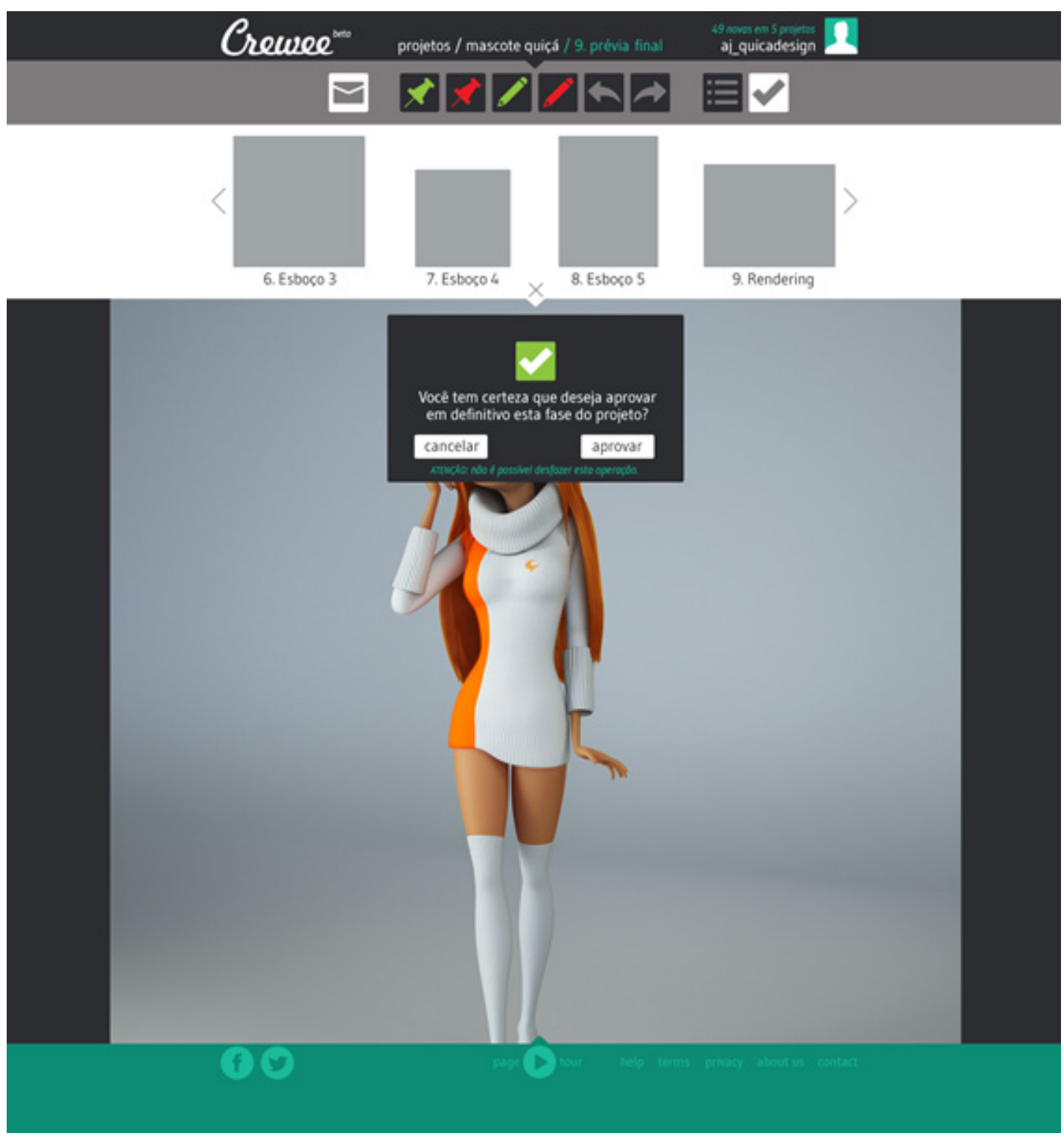

c) Registro prático da evolução do projeto: oficializa as etapas do projeto de modo que o cliente perceba.

d) Contato direto do cliente com a equipe de criação e integração de feedbacks, além da centralização da comunicação entre os envolvidos (empresa de design, designers freelancers, entre outros profissionais). 
Gil, A. G. S. , Lourenço, A. J. M. L. \& Hildebrand, H. R. | Considerações acerca do conceito de projeto de produtos interativos na contemporaneidade. Processo de criação e desenvolvimento do aplicativo Crewee

\subsection{Tecnologias envolvidas para a programação}

13 O Bootstrap Twitter fornece templates HTML, CSS e JS para criação de interfaces. Por ser responsivo, já adéqua o layout das páginas web às diferentes resoluções (Rodella, 2014). Ver também: http://getbootstrap. com/. Acesso em: 24 Set. 2014.
Do lado do servidor, foi utilizada a linguagem de programação Python. Já os padrões de desenvolvimento do front-end foram HTML5 e CSS3 com Java Script e foi utilizado o Bootstrap Twitter ${ }^{13}$, que já é responsivo, como framework.

\subsection{Resultados e possibilidades futuras para o Crewee}

A princípio, o Crewee não cria nenhuma metodologia nova. Seu principal ganho está em conseguir transformar a aplicação de metodologias em algo mais natural colaborando, de modo prático, no gerenciamento do atendimento ao cliente e na comunicação da equipe de profissionais envolvidos. Por isso, seu slogan: "juntos, nós criamos melhor".

O uso do Crewee por equipes de criação e desenvolvimento ajudará no processo de troca de informações entre designers e clientes, uma vez que o processo de design não parte da definição do problema em direção a uma solução, de forma determinista, e sim, a própria definição do problema é modificada, compreendida de diversas formas, conforme o projeto se desenvolve. Parte desse processo de coevolução entre problema e solução fica registrado no aplicativo.

É importante salientar também que existem desafios no que se refere à participação do cliente na tomada de decisões, que são muito mais relacionados ao modo como a equipe conduz o processo do que ao simples uso de uma ferramenta. A ferramenta facilita a participação, mas é papel da equipe criar essa abertura, conscientizar o cliente sobre a forma que a empresa trabalha, sobre suas metodologias e, principalmente, sobre como o cliente também é responsável quando um objetivo é (ou não) atingido.

Como possibilidades futuras, identificamos a evolução do Crewee até se tornar uma ferramenta mais robusta de gestão de projetos, de gerenciamento do relacionamento com o cliente e prospecção, além de desempenhar o papel de ferramenta de gestão financeira e ser um recurso importante de planejamento.

\section{Considerações finais}

O termo "projeto" se expande com os conceitos de metadesign, pois envolve manipular a composição dos procedimentos de projeto, manipular as condicionantes de um espaço de possibilidades.

Acrescentamos que o aplicativo Crewee, abordado no presente artigo, se relaciona com toda a fundamentação teórica sobre métodos e metodologias, não apenas por ter seu processo de criação e desenvolvimento exposto, mas também por se apresentar como uma solução de design para um problema de design: uma solução mais 
Gil, A. G. S. , Lourenço, A. J. M. L. \& Hildebrand, H. R. | Considerações acerca do conceito de projeto de produtos interativos na contemporaneidade. Processo de criação e desenvolvimento do aplicativo Crewee

visual e intuitiva. Além disso, ele se apresenta como objeto complexo, no sentido de manter-se aberto a outras funções, a outras apropriações por parte dos usuários (talvez não previstas no projeto inicial).

A inovação está no uso da imagem como principal componente do gerenciamento, em que o cliente e a equipe de criação podem desenhar diretamente sobre a imagem e fazer observações, que são qualificadas como positivas ou negativas (Figura 5), além da visualização do processo em uma sequencia cronológica (Figura 4), que deixa bastante claro o avanço do projeto e a validação das fases.

Os processos de projeto estão evoluindo em ritmo acelerado na contemporaneidade, e é no fazer que se reinventa o próprio modo de fazer (Pareyson, 1993). Esses modos ou métodos devem servir para levantar possibilidades, fazer questionamentos, muito mais do que solucionar de forma determinista um problema (Flusser, 2007).

\section{Referências}

BROWN, T. 2010. Design Thinking: uma metodologia poderosa para decretar o fim das velhas ideias. Rio de Janeiro: Elsevier.

FLUSSER, V. 2007. O mundo codificado: por uma filosofia do Design e da Comunicação. São Paulo: Cosac Naify.

LÉVY, P. 1998. O que é virtual? São Paulo: Ed. 34.

MORAES, D. 2010. Metaprojeto: O Design do Design. São Paulo: Blucher.

NORMAN, D. 2004. Emotional Design. Why we love (or hate) everyday things. New York: Basic Books.

PAREYSON, L. 1993. Estética: teoria da formatividade. Petrópolis: Vozes.

PREECE, J., ROGERS, Y., SHARP, H. 2005. Design de Interação: além da interação humano-computador. Bookman.

RODELLA, G. 2014. Uma abordagem responsiva para o desenvolvimento de interfaces para sistemas web. Monografia de conclusão de curso de Graduação em Engenharia de Software e Sistemas de Informação. USP São Carlos.

SHEDROFF, N. 2001. Experience design 1. New Riders Publishing.

UTTERBACK, J. 2007. Design Inspired Innovation. United States: World Scientific Pub Co Inc.

VERGANTI, R. 2008. Design, meanings and Radical Innovation: A metamodel and a Research Agenda. The European Journal of Social Sciences: The Journal of Product Innovation Management. V. 25, p. 436-456.

VAN DER LINDEN, J.; LACERDA, A. et al. 2010. A evolução dos métodos projetuais. In: Anais do 9 ${ }^{\underline{0}}$ Congresso Brasileiro de Pesquisa e Desenvolvimento em Design. São Paulo: Blücher e Universidade Anhembi Morumbi. Disponível em: http://blogs.anhembi.br/congressodesign/anais/artigos/anais9PeD2010. pdf. Acesso em 22 jul. 2014.

VASSÃO, C. 2010. Metadesign. Ferramentas, estratégias e ética para a complexidade. São Paulo: Blucher.

VIEIRA, G. 2009. Design e Inovação: Projeto orientado para o mercado e centrado no usuário. In: Convergências: Revista de Investigação e Ensino das Artes. № 4. Disponível em: http://convergencias.esart.ipcb.pt/ artigo/58. Acesso em 22 jul. 2014.

Infodesıgn || São Paulo | v. 12 | n. 1 [2015], p. $33-46$ 
Gil, A. G. S. , Lourenço, A. J. M. L. \& Hildebrand, H. R. | Considerações acerca do conceito de projeto de produtos interativos na contemporaneidade. Processo de criação e desenvolvimento do aplicativo Crewee

\section{Sobre os autores:}

Adeline Gabriela Silva Gil, doutoranda em Artes Visuais pela UNICAMP na linha de pesquisa em multimeios, mestra em Comunicação Midiática pela FAAC - UNESP e bacharel em Desenho Industrial com habilitação em Programação Visual. É diretora de arte na Quiçá Design e docente no Bacharelado em Design na UNIARA. Atua como líder local da IxDA (Interaction Design Association), capítulo de São Carlos. <alunos.adeline@gmail.com>

Antônio José de Moura Leite Lourenço, possui MBA em Marketing e é bacharel em Desenho Industrial com habilitação em Projeto de Produto pela FAAC - UNESP. É sócio diretor da Quiçá Design Produções 3D, empresa especialista em animações tridimensionais, com foco em animações tecnológicas, que tem o objetivo de comunicar ideias com eficácia, utilizando o design como ferramenta catalisadora na relação entre empresas e seus clientes. <antonio@ quicadesign.com.br>

Hermes Renato Hildebrand, doutor em Comunicação e Semiótica pela PUC-SP e mestre em Multimeios pela UNICAMP. É professor da UNICAMP e PUC-SP e coordenador do Programa de Pós-Graduação do TIDD - Tecnologias da Inteligência e Design Digital da PUC-SP. Atua em artes, ciência e tecnologias, desenvolvendo pesquisas e produções em mídias digitais e locativas. Atua no coletivo de artes: SCIArts - Equipe Interdisciplinar. <hrenatoh@gmail.com>

Artigo recebido em 28 nov. 2014, aprovado em 11 jul. 2015. 